\title{
PENGEMBANGAN KREATIVITAS MAHASISWA CALON GURU KIMIA DALAM PEMBELAJARAN DENGAN METODE INKUIRI LABORATORIUM MELALUI TEMA MINUMAN KEMASAN
}

\author{
1). Sari, 2).Hayat Sholihin, 3). Mulyati Arifin \\ 1). Program Studi Pendidikan Kimia Fakultas Tarbiyah dan Keguruan \\ UIN Sunan Gunung Djati Bandung \\ Sekolah Pascasarjana Universitas Pendidikan Indonesia Bandung \\ riechemistry@gmail.com/ 085624212614 \\ 2). Sekolah Pascasarjana Universitas Pendidikan Indonesia Bandung \\ 3). Sekolah Pascasarjana Universitas Pendidikan Indonesia Bandung
}

\begin{abstract}
This study aims to find a laboratory inquiry learning model, obtain a description of students' creativity development, and obtain a description of students' responses toward using laboratory inquiry method with the theme of packaged beverage. The method in this study is quasi-experimental research design using Nonequivalent Control Group Design. The data is collected using creative thinking skill test, observation of attitude and action, as well as questionnaire. Quantitative data is analyzed using statistics. The results showed that the experimental class students experience the creative development from the aspects of creative thinking skills with the highest score is on the ability to think originally with $\mathrm{N}$-gain of 42.13\% in the moderate category. From the aspect of creative attitude, experimental class scores highest on the indicator of feeling challenged by a plurality by the $\mathrm{N}$-gain of $59.25 \%$ in the moderate category. From the aspect of the creative act, the experimental class is highest on the performance aspects of lab implementation stage with average $\mathrm{N}$-gain of $52.88 \%$ in the moderate category. Based on the results of the questionnaire, the students' responses to lab implementation, the ability to understand chemistry concepts through packaged beverage theme and their responses to learning method are positive.
\end{abstract}

Keywords: Creativity, Laboratory Inquiry, Practicum Design

\section{Pendahuluan}

Kualitas pembelajaran harus senantiasa dikembangkan dan diperbarui agar calon guru memiliki kreativitas (keterampilan berpikir kreatif, sikap dan tindakan kreatif). Misalnya, perubahan paradigma dalam pendidikan dan pembelajaran yakni orientasi pembelajaran yang semula berpusat pada guru (teacher centered) menjadi berpusat pada siswa (student centered). Perubahan tersebut dimaksudkan untuk memperbaiki mutu pendidikan, baik dari segi proses maupun hasil pendidikan. Upaya yang dilakukan misalnya dengan melaksanakan suatu metode pembelajaran yang kreatif dan inovatif.

Inkuiri dipandang sebagai salah satu bentuk pembelajaran yang cocok dan lebih menekankan siswa untuk menemukan suatu konsep (Sanjaya, 2010). Pembelajaran inkuiri adalah pusat dari pembelajaran sains di mana calon guru dilibatkan secara langsung dalam perumusan masalah, pembuatan hipotesis, merancang eksperimen, mengumpulkan dan menganalisis data, serta menarik kesimpulan.

Tujuan penelitian ini untuk: mengetahui penerapan metode inkuiri laboratorium melalui Praktikum Kimia Dasar II; Untuk mengetahui peningkatan kreativitas mahasiswa pada aspek sikap kreatif dengan metode inkuiri laboratorium melalui Praktikum Kimia Dasar II; Untuk mengetahui peningkatan kreativitas mahasiswa pada aspek tindakan kreatif dengan metode inkuiri laboratorium melalui Praktikum Kimia Dasar II? 
Menurut Drevdahl kreativitas adalah apapun yang sebelumnya tidak dikenal pembuatnya atau baru.Rothernberg (dalam Hafifah, 2012) mengemukakan kriteria kreativitas meliputi tiga dimensiyaitu :

a. Dimensi Proses

Kreativitas merupakan semua hal yang dihasilkan dari sebuah proses. Proses ini kemudian dihubungkan dengan tahap-tahap berpikir kreatif.

b. Dimensi person

Kriteria kreativitas berdasarkan dimensi person ini identik dengan kepribadian kreatif atau sikap kreatif.Menurut Williams (2013) ciriciri nonaptitude ialah ciri-ciri yang lebih berkaitan dengan sikap atau perasaan, meliputi : rasa ingin tahu, bersifat imajinatif, merasa tertantang oleh kemajemukan, sifat berani mengambil resiko, sifat menghargai.

c. Dimensi produk atau hasil

Kriteria kreativitas berdasarkan dimensi produk seringkali disebut sebagai kriteria puncak.Karena dimensi produk merupakan hasil kerja atau karya seseorang baik dalam bentuk barang, kerajinan maupun penampilan atau pertunjukan serta karangan atau gagasan sering juga disebut tindakan kreatif.Produk kreatif dapat secara langsung menggambarkan seseorang dalam kegiatan kreatif.

\section{Metode Inkuiri}

Menurut Angelo \& Cross (dalam Ibrahim, 2010), langkah metode pembelajaran inkuiri merupakan suatu proses yang dimulai dari:
a. Observasi atau pengamatan terhadap berbagai fenomena alam
b. Mengajukan pertanyaan tentang fenomena yang dihadapi
c. Mengajukan dugaan atau kemungkinan jawaban
d. Mengumpulkan data yang terkait dengan pertanyaan yang diajukan
e. Merumuskan kesimpulan- kesimpulan berdasarkan data.
Materi-materikimia yang dapat dikaji dalam Minuman Kemasan

Minuman sari buah merupakan salah satu jenis koloid sol cair yang medium pendispersinya berupa cairan dan fase terdispersinya berupa padatan (Brady, 2010).Pembuatan minuman sari buah merupakan salah satu contoh pembuatan sistem koloid dengan metode dispersi secara mekanik dari partikel berukuran besar menjadi partikel berukuran kecil.

Dari berbagai jenis minuman kemasan ada beberapa konsep yang dapat kita hubungkan dengan materi perkuliahan Praktikum Kimia Dasar II yaitu konsep larutan elektrolit dan non elektrolit, larutan asam dan basa, koloid, sel volta, sifat koligatif larutan, elektrolisis dan polimer.

\section{Metode dan Instrumen Penelitian}

Metode penelitian yang digunakanadalah penelitian quasi experiment. Dengan desain penelitian nonequivalent control group design Wiersma \& Jurs (2009).

Subjek dalam penelitian ini adalah mahasiswa pendidikan kimia semester 1 di salah satu perguruan tinggi di Bandung. Instrumen dalam penelitian ini berupa deskripsi pembelajaran, tes keterampilan berpikir kreatif, observasi sikap dan tindakan kreatif mahasiswa.Analisis data dilakukan dengan menggunakan statistik.

\section{Hasil dan Pembahasan}

Desain Pembelajaran dengan Metode Inkuiri Laboratorium melalui Tema Minuman Kemasan

Berdasarkan langkah-langkah pembelajaran dengan menggunakan metode inkuiri laboratorium melalui tema minuman kemasan yang telah dilakukan, maka diperoleh desain pembelajaran metode inkuiri laboratorium sebagai berikut: 1) Observasi terhadap data atau fenomena yang diberikan, 2) Menemukan masalah, 3) Mengajukan pertanyaan,4) Membuat hipotesis, 5) Membuat desain praktikum berdasarkan hipotesis masingmasing kelompok, 6) Menguji desain dan hipotesis masing-masing kelompok, 7) Mengumpulkan data yang diperoleh dari 
hasil praktikum , 8) Mengkomunikasikan data hasil praktikum , 9) Membuat kesimpulan.

Berdasarkan desain pembelajaran metode inkuiri yang diperoleh, terdapat perbedaan dengan metode inkuiri pada umumnya dalam tahapan merumuskan masalah dan membuat desain praktikum berdasarkan hipotesis yang telah dibuat.

Berdasarkan temuan terdapat 13 judul percobaan. Sembilan judul percobaan berhubungan dengan konsep kimia dasar II yaitu konsep koloid, asam basa, larutan elektrolit, sel volta, elektrolisis, sifat koligatif larutan, karbohidrat, dan polimer, terdapat 4 judul yang tidak termasuk dalam konsep kimia dasar II yaitu mikrobiologi, pengujian kadar gula, vitamin $\mathrm{C}$, dan zat aditif.

Berdasarkantemuandi atas dapat diketahui bahwa pembelajaran dengan metode inkuiri laboratorium melalui tema minuman kemasan dapat meningkatkan rasa ingin tahu bila dilihat dari hasil pertanyaan yang diajukan mahasiswa ketika proses pembelajaran berlangsung. Hal ini disebabkan pembelajaran dengan metode inkuiri memberikan kesempatan kepada mahasiswa untuk mengajukan pertanyaan dan menggunakan fakta untuk menjawab pertanyaan tersebut. Dalam proses pembelajaran inkuiri, mahasiswa belajar untuk melakukan investigasi dan mengumpulkan data dari berbagai sumber, mengembangkan suatu penjelasan dari data, dan mengkomunikasikannya serta menentukan kesimpulan. Hal ini sesuai dengan pendapat dari Angelo \& Cross (dalam Ibrahim, 2010) langkah metode pembelajaran inkuiri merupakan suatu siklus yang dimulai dari:

a. Observasi atau pengamatan terhadap berbagai fenomena alam

b. Mengajukan pertanyaan tentang fenomena yang dihadapi

c. Mengajukan dugaan atau kemungkinan jawaban

d. Mengumpulkan data yang terkait dengan pertanyaan yang diajukan

e. Merumuskan kesimpulankesimpulan berdasarkan data.

Pembelajaran metode inkuiri laboratorium melalui tema minuman kemasan dapat mengaplikasikan 13 konsep kimia, tema minuman kemasan memberikan pengalaman langsung kepada siswa, dengan pengalaman langsung, siswa dihadapkan pada sesuatu yang nyata sebagai dasar untuk memahami hal-hal yang lebih abstrak. Hal ini sejalan dengan tujuan dari metode inkuiri seperti yang kemukakan oleh Sanjaya (2010) tujuan utama dari pembelajaran inkuiri adalah pengembangan kemampuan berpikir. Oleh karena itu proses pembelajaran inkuiri bukan ditentukan oleh sejauh mana siswa dapat menguasai materi pelajaran, akan tetapi sejauh mana siswa berkreativitas mencari dan menemukan suatu konsep.

Pengembangan Kreativitas pada Aspek Keterampilan Berpikir Kreatif Kelas Kontrol dan Eksperimen

Hasil pengembangan kreativitas mahasiswa pada aspek keterampilan berpikir kreatif dapat dilihat pada tabel 1 .

Tabel 1 Persentase Rerata Pretes, Postes dan N-Gain Perindikator Aspek Keterampilan Berpikir Kreatif Kelas Kontrol dan Eksperimen

\begin{tabular}{|c|l|c|c|c|c|c|c|}
\hline \multirow{2}{*}{ No } & \multirow{2}{*}{ Indikator } & \multicolumn{3}{|c|}{ Kelas Kontrol } & \multicolumn{3}{c|}{ Kelas Eksperimen } \\
\cline { 3 - 8 } & & Pretes & Postes & N-gain & Pretes & Postes & N-gain \\
\hline 1 & Kemampuan berpikir lancar & 54,20 & 60,70 & 14,19 & 53,66 & 65,58 & 25,72 \\
\hline 2 & Kemampuan berpikir luwes & 59,62 & 65,04 & 13,42 & 57,72 & 72,90 & 35,90 \\
\hline 3 & Kemampuan berpikir orisinil & 70,26 & 68,63 & $-5,48$ & 59,96 & 76,83 & 42,13 \\
\hline 4 & Kemampuan merinci & 63,41 & 63,41 & 0,00 & 60,98 & 73,98 & 33,32 \\
\hline 5 & Kemampuan menilai & 59,35 & 66,26 & 17,00 & 59,76 & 60,57 & 2,01 \\
\hline \multicolumn{2}{|c|}{ Rata-rata } & $\mathbf{6 1 , 3 7}$ & $\mathbf{6 4 , 8 1}$ & $\mathbf{7 , 8 3}$ & $\mathbf{5 8 , 4 2}$ & $\mathbf{6 9 , 9 7}$ & $\mathbf{2 7 , 8 2}$ \\
\hline
\end{tabular}


Perolehan N-gain tertinggi aspek keterampilan berpikir kreatif pada kelas kontrol terdapat pada indikator kemampuan menilai yaitu sebesar $17 \%$ dengan kategori rendah, dan terrendah terjadi pada indikator kemampuan orisinil yaitu sebesar 5,48\% dengan kategori rendah hal ini disebabkan cara berpikir mahasiswa pada kelas kontrol relatif sama dan sebagian kecil mahasiswa memiliki cara berpikir lain dari pada cara lainnya. $\mathrm{N}$-gain yang tidak mengalami kenaikan pada kelas kontrol adalah kemampuan merinci, ditandai dengan kemampuan mahasiswa tidak mengalami perubahan dalam memilih rasa keindahan yang kuat dengan menambahkan atau memperkaya garis-garis warna atau detail gambar produk sendiri atau produk orang lain.

Perolehan N-gain tertinggi aspek keterampilan berpikir kreatif pada kelas eksperimen terdapat pada indikator kemampuan orisinil yaitu sebesar $42,13 \%$ dengan kategori sedang, hal ini ditandai dengan kemampuan mahasiswa dalam melakukan langkah baru dan memilih cara berpikir yang lain dari pada cara lainnya dan terendah terjadi pada indikator kemampuan menilai 2,01 \% dengan kategori rendah. Secara keseluruhan diperoleh rerata nilai $\mathrm{N}$-gain kelas kontrol sebesar $7,83 \%$ dan kelas eksperimen sebesar 27,82\%. Dari data tersebut diketahui bahwa terjadi pengembangan kreativitas pada aspek keterampilan berpikir kreatif antara kelas kontrol dan eksperimen.

Berdasarkan hasilperhitungan dengan membandingkan pretes dan postes dapat diketahui bahwa pembelajaran dengan metode inkuiri laboratorium melalui tema minuman kemasan dapat mengembangan kreativitas kelas eksperimen pada aspek keterampilan berpikir kreatif indikator kemampuan berpikir orisinil dengan kategori sedang. Hal ini disebabkan pada pembelajaran menggunakan metode inkuiri mahasiswa tidak terpaku pada prosedur praktikum yang ditetapkan akan tetapi mahasiswa dikendalikan oleh pertanyaan yang membutuhkan ikatan pengetahuan yang berkelanjutan dengan menggunakan kemampuan berpikir yang lebih tinggi untuk membuat pemikiran dan kinerja mandiri, dan menuntun mahasiswa fokus pada kegiatan dalam mengumpulkan dan menginterpretasi data untuk menemukan konsep baru, prinsip, atau hukum, dengan demikian membuat sesuatu yang konkret menjadi abstrak, hal tersebut merupakan ciri pembelajaran inkuiri (Wenning, 2005).

Pada kelas eksperimen selain mengalami pengembangan kreativitas pada aspek keterampilan berpikir kreatif indikator kemampuan berpikir orisinil dengan kategori sedang, $\mathrm{N}$-gain terrendah pada indikator kemampuan menilai sebesar 2,01 dengan kategori rendah. Perolehan terkecil pada indikator ini diindikasikan karena pembelajaran dengan metode inkuiri laboratorium melalui tema minuman kemasan mahasiswa lebih tertarik mengkonsumsi minuman kemasan yang mengandung zat aditif dibanding air mineral, meskipun mahasiswa mengetahui dampak negatif dari minuman kemasan tersebut.Menurut Torrance dkk.(1992) kemampuan menilai merupakan suatu rencana sehat atau suatu tindakan bijaksana, mampu mengambil keputusan terhadap situasi yang terbuka dan tidak hanya mencetuskan gagasan, tetapi juga melaksanakannya.

Pengembangan Kreativitas pada Aspek Sikap Kreatif tiap Indikator Kelas Kontrol dan Eksperimen

Hasil pengembangan kreativitas mahasiswa pada aspek sikap kreatif dapat dilihat pada tabel di bawah ini:

Tabel 2 Skor Rerata Pretes Postes Sikap Kreatif Perindikator Kelas Kontrol dan Eksperimen

\begin{tabular}{|l|l|c|c|c|c|c|c|}
\hline \multirow{2}{*}{ No } & \multirow{2}{*}{ Indikator } & \multicolumn{3}{|c|}{ Kelas Kontrol } & \multicolumn{3}{c|}{ Kelas Eksperimen } \\
\cline { 3 - 8 } & & Awal & Akhir & N-gain & Awal & Akhir & N-gain \\
\hline 1 & Rasa ingin tahu & 39,02 & 42,68 & 6,00 & 25,61 & 60,98 & 47,55 \\
\hline
\end{tabular}




\begin{tabular}{|l|l|c|c|c|c|c|c|}
\hline \multirow{2}{*}{ No } & \multicolumn{2}{|c|}{ Indikator } & \multicolumn{3}{c|}{ Kelas Kontrol } & \multicolumn{3}{c|}{ Kelas Eksperimen } \\
\cline { 3 - 8 } & Awal & Akhir & N-gain & Awal & Akhir & N-gain \\
\hline 2 & Bersifat imajinatif & 34,15 & 34,15 & 0,00 & 41,46 & 68,29 & 45,83 \\
\hline 3 & $\begin{array}{l}\text { Merasa tertantang oleh } \\
\text { kemajemukan }\end{array}$ & 73,98 & 75,61 & 6,26 & 78,06 & 91,06 & 59,25 \\
\hline 4 & $\begin{array}{l}\text { Sifat berani mengambil } \\
\text { resiko }\end{array}$ & 57,93 & 57,93 & 0,00 & 68,29 & 73,78 & 17,31 \\
\hline 5 & Sifat menghargai & 47,97 & 50,41 & 4,69 & 59,35 & 61,79 & 6,00 \\
\hline \multicolumn{1}{|l|}{ Rata-rata } & $\mathbf{5 0 , 6 1}$ & $\mathbf{5 2 , 1 6}$ & $\mathbf{3 , 3 9}$ & $\mathbf{5 4 , 5 5}$ & $\mathbf{7 1 , 1 8}$ & $\mathbf{3 5 , 1 9}$ \\
\hline
\end{tabular}

Berdasarkan Tabel 2 terlihat bahwa perolehan $\mathrm{N}$-gain tertinggi pada kelas kontrol terdapat pada indikator merasa tertantang oleh kemajemukan sebesar 6,26\% dengan kategori rendah, dan $\mathrm{N}$-gain yang tidak mengalami perubahan pada indikator bersifat imajinatif dan sifat berani mengambil resiko dengan kategori rendah. Berdasarkan data tersebut dapat diketahui bahwa pada kelas kontrol mahasiswa mengalami kenaikan dalam sikap melibatkan diri dalam tugas-tugas yang majemuk, mencari penyelesaian tanpa bantuan orang lain dan berusaha terus menerus agar berhasil. Perolehan Ngain tertinggi pada kelas eksperimen terdapat pada indikator merasa tertantang oleh kemajemukan yaitu sebesar 59,25\% dengan kategori sedang dan terendah terjadi pada sikap menghargai sebesar 6,00 $\%$ dengan kategori rendah. Berdasarkan data tersebut dapat diketahui bahwa pada kelas ekaperimen mahasiswa mengalami kenaikan dalam sikap merasa tertantang oleh kemajemukan, hal ini ditandai dengan mencari penyelesaian tanpa bantuan orang lain, tidak cenderung mencari jalan tergampang, berusaha terus-menerus agar berhasil dibanding kelas kontrol.

Berdasarkan hasilperhitungan dengan membandingkan pretes dan postes dapat diketahui bahwa pembelajaran dengan metode inkuiri laboratorium melalui tema minuman kemasan dapat mengembangan kreativitas kelas eksperimen pada aspek sikap kreatif indikator merasa tertantang oleh kemajemukan. Hal ini disebabkan pada pembelajaran menggunakan metode inkuiri memberikan kesempatan kepada mahasiswa untuk memahami dari kesalahan-kesalahan mereka dan kesalahan dalam langkah percobaan, serta menyediakan waktu dan kesempatan pada siswa untuk membuat dan memperbaiki dari kesalahan. Sehingga hal ini diasumsikan mendorong sikap siswa untuk berbuat lebih banyak (Wenning, 2005). Menurut Williams (2013) salah satu sikap kreatif ditunjukan dengan mencari penyelesaian tanpa bantuan orang lain dan berusaha terus-menerus agar berhasil.

Pengembangan Kreativitas pada Aspek Tindakan Kreatif tiap Indikator Kelas Kontrol dan Eksperimen

Berdasarkan tabel 3di bawah ini terlihat bahwa perolehan $\mathrm{N}$-gain pada aspek kinerja tahap persiapan praktikum kelas kontrol dan eksperimen terdapat pada indikator memeriksa kelengkapan alat yang diperlukan pada kegiatan praktikum, $\mathrm{N}$-gain kelas kontrol sebesar $11,75 \%$, pada kelas eksperimen sebesar $60 \%$. Pada aspek kinerja tahap pelaksanaan praktikum kelas kontrol terdapat pada indikator membuat jurnal praktikum sebesar 7,70\%. Pada kelas eksperimen $\mathrm{N}$-gain tertinggi terdapat pada indikator melakukan pengamatan sebesar $47,1 \%$.

Pada aspek kinerja pembuatan desain praktikum perolehan $\mathrm{N}$-gain tertinggi pada kelas kontrol terdapat pada indikator rancangan alat dan bahan sebesar 32,01\% dengan kategori rendah dan $\mathrm{N}$-gain terrendah terdapat pada indikator rancangan prosedur percobaan sebesar $6,67 \%$. Kelas eksperimen perolehan Ngain tertinggi terdapat pada indikator merumuskan hipotesis dan merumuskan tujuan sebesar $89,02 \%$ dan terrendah terdapat pada indikator rancangan prosedur percobaan sebesar $66,67 \%$. 
Berdasarkan hasilperhitungan dengan membandingkan pretes dan postes dapat diketahui bahwa pembelajaran dengan metode inkuiri laboratorium melalui tema minuman kemasan dapat mengembangan kreativitas kelas eksperimen aspek tindakan kreatif pada aspek kinerja persiapan praktikum. Hal ini disebabkan pada pembelajaran menggunakan metode inkuiri memberikan kesempatan kepada siswa untuk menciptakan desain eksperimen yang dikontrol diri sendiri, membutuhkan siswa untuk secara mandiri mengidentifikasi, membedakan, dan mengontrol keterkaitan variabel bebas dan variabel kontrol, membuat siswa memahami penyelidikan sains, serta menggunakan prosedur yang lebih konsisten dengan pelaksanakan sains yang autentik, menunjukkan bahwa langkah sainsnya berulang dan mengkoreksi diri sendiri (Wenning, 2005). Menurut Arifin dkk.(2005) metode inkuiri memberikan kesempatan siswa untuk berpartisipasi secara aktif dan melakukan eksperimen-eksperimen yang memberikan kesempatan siswa untuk menemukan konsep dan prinsip-prinsip sendiri. Ternyata pengembangan berpikir yang menggunakan proses ini berhasil menjadi bagian yang penting dari kegiatan belajar mengajar. Arifin dkk. (2005) mengemukakan bahwa pembelajaran inkuiri pasti akan memberikan kesempatan mengembangkan kreativitas sepanjang pembelajaran tersebut memberikan kesempatan siswa untuk "menemukan" sesuatu yang baru.

\section{Kesimpulan dan Saran}

Hasil penelitian menunjukan bahwa terdapat pengembanngan kreativitas pada aspek keterampilan berpikir kreatif tertinggi terdapat pada kemampuan orisinil dengan perolehan $\mathrm{N}$-gain sebesar 42,13\% dengan kategori sedang. Pada aspek sikap kreatif kelas eksperimen tertinggi terdapat pada indikator merasa tertantang oleh kemajemukan dengan $\mathrm{N}$-gain sebesar $59,25 \%$ dengan kategori sedang. Pada aspek tindakan kreatif $\mathrm{N}$-gain tertinggi terdapat pada tahap pelaksanaan praktikum sebesar 52,88\% dengan kategori sedang.

Berdasarkan penelitian yang telah dilakukan maka dapat disarankan hal-hal sebagai berikut: Pembelajaran dengan menggunakan metode inkuiri laboratorium dapat digunakan sebagai alternatif bagi para pengajar matakuliah kimia dasar.

Melihat perbedaan yang signifikan pengembangan kreativitas mahasiswa antara kelompok kontrol dan eksperimen, maka selayaknya para dosen atau guru untuk meningkatkan kreativitasnya dengan menggunakan metode yang lainnya. Sehubungan dengan implementasi pembelajaran dengan metode inkuiri laboratorium memerlukan waktu yang relatif lama, sehingga dosen harus betulbetul mamapu mendesain pembelajaran sesuai waktu yang tersedia.

\section{Daftar Pustaka}

Arifin, M. dkk. (2005). Strategi Belajar Mengajar Kimia. Malang: UM Press.

Brady, J. E. (2010). Kimia Universitas: Asas \& Struktur, Jilid 1. Tangerang: Bina Rupa Aksara.

Drevdahldalam Hurlock. B. H. (1978). Perkembangan Anak. Edisi Ke Enam. Jakarta: Erlangga.

Hafifah, H. (2012). Kriteria Pengembangan Kreativitas Siswa. [online] Tersedia: http://hananuayhafifah.blogspot.com [ 03/ 2012/03].

Hurlock. B. H. (1978). Perkembangan Anak. Edisi Ke Enam. Jakarta: Erlangga.

Ibrahim, M. (2010).Model Pembelajaran Inkuiri. [Online]. Tersedia: http://fisika21.wordpress.com [24 Agustus 2012].

Johari dan Rachmawati. (2009). Kimia 2 SMA dan MA untuk kelas XI. Jakarta: Esis.

Minner, D. dkk. (2009). Inquiry-Based Science Instruction What Is It and Does It Matter. Journal of research in science teaching. 
Sanjaya, W.H. (2010). Strategi Pembelajaran Berorientasi Standar Proses Pendidikan. (Edisi Kesatu). Jakarta: Pranada Media Grup.

Wenning, J.C (2007). Levels of inquary Model of Science Teaching and Learning Sequences to Lesson Plans. Departemen of Physics, Illionds State University. Konodas GilgitBaltistan, Pakistan.

Wiersma, W. \& Jurs, G.S. (2009). Research Methods in Education an Introducation. Nine Edition, United State of America, Pearson.

Williams, G.S. (2013). Improving problem Based Learning in Creative Communities Through Effective Group Evaluation. Interdisciplinary Journal of Problem-Base-Learning. 
